\title{
Microwave-assisted wet chemical synthesis: advantages, significance, and steps to industrialization
}

\author{
Shangzhao Shi and Jiann-Yang Hwang ${ }^{*}$ \\ Institute of Materials Processing, Department of Materials Science and Engineering \\ Michigan Technological University \\ Houghton, MI 49931
}

Previous research has revealed several advantages from microwave-assisted wet chemical synthesis in reaction acceleration, yield improvement, enhanced physicochemical properties and the evolvement of new material phases. The study present examples that demonstrate the significance of these advantages to industrial application. In order to achieve successful industrial application there is a need to distinguish between the microwave athermal (not excited by heat) effect from the microwave-induced thermal effect (temperature rise). The optimization of this new process has to be systematically investigated, so the advantages and benefits of this new technology can be fully exploited.

\section{Advantages and significance}

\section{?- $\mathrm{Fe}_{2} \mathrm{O}_{3}$ based magnetic materials}

?- $\mathrm{Fe}_{2} \mathrm{O}_{3}$ based magnetic materials have been extensively used as recording materials because of their good magnetic properties. The emergence of nanomagnetic technology has imposed new demands upon magnetic materials. To fabricate ultrahigh density and ultrahigh speed data storage devices, which work on the magnetic-spintronic concept, magnetic materials with nanoscale particles are highly preferred ${ }^{1}$.

Conventionally, ?- $\mathrm{Fe}_{2} \mathrm{O}_{3}$ powders with monodispersed particles are synthesized first by means of forced hydrolysis of ferric nitrate or ferric chloride in aqueous solutions, which produces $\alpha-\mathrm{Fe}_{2} \mathrm{O}_{3}$, and then the $\alpha-\mathrm{Fe}_{2} \mathrm{O}_{3}$ are transformed into ?- $\mathrm{Fe}_{2} \mathrm{O}_{3}$ in a high-temperature process $^{2,}{ }^{3}$. To effectively control the particle shape and particle size, which are essential for achieving the desired magnetic properties, the hydrolysis solution must be very dilute. For producing micron- and submicron-sized particles, the concentrations of the ferric irons are generally within a range around $0.02 \mathrm{M}^{2,4,5}$ and for producing nanosized powders, the ferric concentration should be much lower. In addition to dilute solutions, the conventional hydrolysis has to be carefully controlled and it generally requires 2-7 days. This means that, even based upon the shortest processing time and highest concentration, the rate for producing the nanosized iron oxide powders would be less than 0.014 gram per liter per hour. In order to use nanosized magnetic materials for industrial applications, appreciable acceleration of the process and an increase in the ferric concentration are required.

Several researchers have attempted the iron oxide synthesis via microwave-assisted hydrolysis. Komarneni et al demonstrated that under otherwise identical processing conditions, synthesis of crystalline hematite by a microwave-hydrothermal approach was 36 times faster than by conventional hydrothermal methods ${ }^{6}$. Our study shows the capability of controlling the particle shape and particle size with this rapid synthesis approach. Rigneau et al further shortened the processing time to 30 minutes and also increased the ferric concentration to $0.05 \mathrm{M}^{7}$, which could increase the production rate over one hundred times. The even more striking finding from their results was that the microwave synthesized $\mathrm{Fe}_{2} \mathrm{O}_{3}$ particles were nano scale and directly ?type. The significance of this finding is that it could not only remarkably simplify the synthesis procedure, but also get rid of the difficulties involved with the calcination of nano powders, and

\footnotetext{
Author to whom correspondence should be addressed
} 
avoid the detrimental microstructure changes that accompany the transformation from $\alpha-\mathrm{Fe}_{2} \mathrm{O}_{3}$ to ?- $\mathrm{Fe}_{2} \mathrm{O}_{3}$ in the conventional high temperature process.

\section{Insertion electrode materials}

The role of intercalation/insertion reactions in battery electrodes was first recognized about 30 years ago. From the first prototype titanium disulfide cells, the technology has more recently been commercialized in Li-ion cells using a cobalt oxide insertion cathode and a carbon insertion anode. This technology has proven highly successful in small devices. Since the conduction species intercalated in the structure exhibit very good electrical conductivity, insertion electrode materials are also considered most promising in large device and large-scale applications ${ }^{8}$.

The extensive research and development on new insertion materials can be recognized from Whittinghan's Work. His investigation has covered a diverse group of layered and intercalated compounds including titanium disulfide ${ }^{9,}{ }^{10}$, lithium cobalt oxide ${ }^{11}$, tetramethylammonium intercalated vanadium oxides ${ }^{12}$, layered-structure manganese dioxides ${ }^{13}$ and vanadium-pillared manganese oxide structures ${ }^{14}$. More recently, the group is investigating vanadium oxide nanotubes, which is considered to have significant advantages due to its distinct electrical contact regions and electrolyte-filled channels ${ }^{15}$.

The insertion materials are normally synthesized via conventional hydrothermal method. The synthesis is a tedious procedure and often takes several days to a week. The use of the microwave method has been attempted to accelerate the synthesis of layered vanadium oxide inserted with tetramethylammonium ions ${ }^{12}$. It was found that this method could reduce the synthesis time to 30 minutes and also found that longer microwave hydrothermal treatment could lead to a new material structure. The adoption of the microwave method to the insertion material synthesis could not only develop a highly efficient, low cost process for synthesis of insertion materials synthesis, but also offer chances to generate new material structures that could not be obtained from conventional methods.

\section{Molecular sieves}

Crystalline molecular sieves have intraframework cages and channels of uniform microporous or mesoporous size, tailor-made acidity or basicity, and high thermal stability. Owing to these unique structures, the materials have acquired various applications in the petroleum refining and petrochemical industry ${ }^{16}$. The advent of nanotechnology has provided a new field for their application. The materials can be used as a high performance nanostrucutured host for preparation of advanced materials that exhibit specific optic, optoelectronic, and electrochemical properties suitable for molecular wire, quantum electronics and non-linear optical devices. A number of preparations of nanoscale materials on such a nanostructured template have been demonstrated including the synthesis of organized metal clusters, metal oxides or sulfides, isolated conducting polymers as well as confined supermolecular compounds ${ }^{17-30}$.

The structure of the molecular sieve frameworks is of great diversity. It is sensitive to synthesis conditions. Generally, it takes several days to several weeks for obtaining the desired material. Raising the temperature may shorten the synthesis time but could result in different structures. There are often several structures concurrently in development. Although each structure may have a dominating stage, the product is more liable to mixed structures ${ }^{31}$. The process is often complicated and time-consuming for synthesizing a pure product with tailored structure.

Microwave-assisted synthesis has been attempted on a certain types of molecular sieves. Significant kinetic acceleration has been demonstrated in synthesis of MgAPO-5 (20min microwave $v s 24 \mathrm{~h}$ conventional) by Cresswell et $a l^{32}$ and in synthesis of MCM-41 (4h microwave vs 7-14d conventional) by U. Oberhagemann et $a l^{33}$. The microwave method is also produces high surface area structures. While multi-point surface area of the conventional synthesized MgAPO-5 is only $4.48 \mathrm{mg}^{2}$, that of the microwave synthesized MgAPO-5 attains $34.97 \mathrm{~m}^{2} \mathrm{~g}^{-1}$, 
about 7 times surface enlargement. The microwave method further shows its effectiveness in producing pure structures, as were the cases for the synthesis of $\mathrm{AlPO}_{4}-11$ and the synthesis of cloverite (Park et $a l^{34}$ ). In these instances, the microwave method was able to obtain these pure crystalline phases in $2.5 \mathrm{~h}$ and $2.7 \mathrm{~h}$ respectively, whereas over 1day conventional preparation produced $\mathrm{AlPO}_{4}-11$ mixed with some amount of $\mathrm{AlPO}_{4}-31$ and a trace of AlPO-tridymite, or produced cloverite with unreacted reactants. Further advantage of the microwave approach was found in the ease of processing stage control. Carmona et $a l^{35}$ investigated the microwave-assisted synthesis of VPI-5 along with conventional approaches. With microwave-activated refluxing method, pure VPI-5 was the only product of the process. With other methods, however, several phases appeared as the processing proceeded.

\section{Organometallic compounds}

Organometallic compounds are generally defined as having a metalcarbon bond with properties distinct from those of inorganic compounds. Orgaometallic compounds cover a large number of varieties, which contain many kinds of metal elements. Some groups have high reactivity and reaction selectivity and are used as various kinds of catalysts or as organosynthetic reagents. Others have chemical stability and have acquired their applications in microbiocides, pesticides, anticancer agents, water repellants, octane number improvement, and antifoaming and mold releasing. Organometallic compounds are also employed as precursors for preparing ultrahigh purity metals and functional ceramics with tailored compositions and structures, such as semiconductor elements, electroconductive materials, magnetic materials, hard materials, heatresistant materials and superconductive materials, etc ${ }^{36}$.

Preparation of organometallic compounds involves reactions of metal elements, metal salts or other organometallic intermediates with inorganic compounds, gases or organic reagents ${ }^{37}$. The synthesis rate varies considerably, with a few that are within one hour ${ }^{38}$ but a number of others require several hours or even days ${ }^{39}$.

The microwave-enhanced kinetics in synthesis of organometallic compounds was reported by Gedye et $a t^{40}$ in 1991 , when they synthesized $\left(\mathrm{C}_{6} \mathrm{H}_{5}\right)_{3} \mathrm{SnCl}$ and $\left(\mathrm{C}_{6} \mathrm{H}_{5}\right)_{3} \mathrm{SnOH}$ in sealed vessels under microwave radiation in 7 and 4 minutes respectively, whereas with conventional reflux method, the synthesis times were correspondingly 3 hours and 1 hour. Laurent et al $t^{11}$ reported microwave-assisted synthesis of alkyl- or arylhalogermanes by means of Redistribution Reactions. With $\mathrm{AlCl}_{3}$ as the catalyst, $\mathrm{Bu}_{3} \mathrm{GeCl}$ was synthesized in an open reactor in $85 \%$ yield in 3 minutes. The kinetic enhancement was remarkable compared to conventional synthesis that requires 5 hours at $200^{\circ} \mathrm{C}$. Vanatta et $a l^{42}$ studied the application of microwave method to the synthesis of Group 6 (Cr, Mo, W) zerovalent organometallic carbonyl compounds. A rateenhancement of up to two orders of magnitude and a higher yield of microwave-assisted synthesis were achieved compared to conventional reflux method.

Table 1. Synthesis of Group $6(\mathrm{Cr}, \mathrm{Mo}, \mathrm{W})$ zerovalent organometallic carbonyl compounds: Microwave vs reflux

\begin{tabular}{|c|c|c|c|c|}
\hline Compound & Time (min) & Temp $\left({ }^{\circ} \mathrm{C}\right)$ & Yield (\%) & Rate enhancement \\
\hline$\left(\mathrm{dppe}^{\mathbf{\mathbf { I }}}\right) \mathrm{Mo}(\mathrm{CO})_{4}$ & $0.5 / 25^{\#}$ & $180 / 120$ & $80 / 68$ & 50 \\
\hline$\left(\mathrm{dppe}^{\mathbf{\nabla}}\right) \mathrm{Mo}(\mathrm{CO})_{4}$ & $2 / 180$ & $180 / 155$ & $64 / 55$ & 90 \\
\hline$\left(\right.$ bipy $\left.^{\star}\right) \mathrm{Mo}(\mathrm{CO})_{4}$ & $0.5 / 90$ & $180 / 110$ & $99 / 88$ & 180 \\
\hline$($ dppe $) \mathrm{Cr}(\mathrm{CO})_{4}$ & $0.5 / 135$ & $180 / 135$ & $86 / 41$ & 270 \\
\hline$\left(\mathrm{dppm}^{\curlyvee}\right) \mathrm{W}(\mathrm{CO})_{4}$ & $5 / 2880$ & $180 / 165$ & $62 / 51$ & 576 \\
\hline
\end{tabular}




\section{Polymers}

$\operatorname{Poly}(\varepsilon$-caprolactam) is an important engineering thermoplastics with a combination of useful thermal and mechanical properties. Its synthetic fiber is widely used and has a global production of more than 3.3 million metric tons. A commercial route to manufacture the polymer is hydrolytic polymerization, which is conventionally carried out in a high pressure reactor at 250$270^{\circ} \mathrm{C}$ for about $12-24 \mathrm{~h}$. Fang et $\mathrm{al}^{43}$ synthesized Poly $(\varepsilon$-caprolactam $)$ by means of microwaveassisted polymerization in nitrogen at atmospheric pressure. At $250^{\circ} \mathrm{C}$ for only $2 \mathrm{~h}$, the synthesis was completed with yield, purity, yield strength and tensile strength comparable to the commercial product.

Poly ( $\varepsilon$-caprolactone) is one of the industrial biopolymers that is used as degradable biomedical and packaging material. It is generally prepared from catalyzed ring-opening polymerization of $\varepsilon$-caprolactone in bulk or solution. Although many efforts have been made to catalyze the process, it still takes over $10 \mathrm{~h}$ or several days to get the polymerization completed. Liao et $\mathrm{al}^{44}$ attempted the microwave-assisted ring-opening polymerization of $\varepsilon$-caprolactone in sealed ampoules. Using $0.1 \%(\mathrm{~mol} / \mathrm{mol})$ stannous octanoate as catalyst, they synthesized the polymer at $180^{\circ} \mathrm{C}$ in $30 \mathrm{~min}$. The yield attained $90 \%$ and the average molar mass is $124000 \mathrm{~g} / \mathrm{mol}$. While in the atmospheric nitrogen environment ${ }^{43}$, Poly $(\varepsilon$-caprolactone) was synthesized via microwave method at $150^{\circ} \mathrm{C}$ in $2 \mathrm{~h}$. Besides the attainment of $92.3 \%$ yield and the comparable yield strain and the tensile modulus, the tensile strength and the strain at break were much higher than those of the conventionally produced polymer.

Fang et $\mathrm{at}^{45}$ also conducted the microwave synthesis of Poly( $\varepsilon$-caprolactam-co- $\varepsilon$ caprolactone), which is viewed as a engineering plastic combining the advantages of the beneficial mechanical and biodegradable properties from its amide and ester constituents. They found that microwave synthesis had obtained higher yields and higher amide-to-ester ratios than conventional thermal approaches of identical conditions.

Recently, more attention has been paid to the synthesis of optically active polymers. These polymers are important in biology and have applications in asymmetric synthesis, in chromatographic techniques and in ferroelectric and nonlinear optical devices. Microwaveassisted synthesis of the optically active poly(amide-imide) was attempted by Mallakpour et $\mathrm{a}^{46,}$ ${ }^{47}$, who demonstrated that the synthesis could be completed within $10 \mathrm{~min}$ and the synthesized polymers had higher inherent viscosity than those obtained from 5-h conventional synthesis.

Conjugated polyarylenes are electroluminescent polymers for display applications. To obtain optimized emissive properties, macromolecular structures with specific functionality should be carefully designed and synthesized. Conventionally the synthesis is by a route involving $\mathrm{Ni}(0)$ mediated coupling polymerization reactions, which is labor intensive and time-consuming (up to $24 \mathrm{~h}$ ). Furthermore, due to the sensitivity (to oxygen and other impurities) of the reactions and the precipitation of certain monomers and the resultant polymers, it is difficult to obtain precise batch-to-batch reproducibility and to control the molecular weight. Carter ${ }^{48}$ utilized microwaveassisted chemistry to overcome these problems. With conditions identical to conventional methods, the microwave approach is able to drive the polymerization to completion in 10 min. The fast polymerization suppressed the side pathways to undesired products, oxidation of catalyst or reactions with glassware and conversion rate of $>99.5 \%$ was observed. The precipitation of polymers from the reaction solution was eliminated even when molecular weights higher than 100,000 were reached, which ensured the control of the molecular weight by adding varying quantities of chain end-capping reagent to the reaction mixture. The synthesis can also be simplified to a one-step, one-pot fashion since the separate catalyst activation step is no longer necessary. 


\section{Steps to industrialization}

Microwave-assisted wet chemical synthesis offers so many significant advantages over conventional methods, that wide application of this technology in industry is a certainty. Compared to solid state materials processing, microwave-assisted wet chemical synthesis is more facile for scaling up. The fluidic reaction contents can be easily homogenized and non-uniformity of microwave energy dissipation inside the reactor, which is a common problem in microwaveassisted solid state processing, is therefore completely eliminated.

This situation, however, still can not guarantee successful application of the microwave technology to industries. Much effort is needed to get a more comprehensive understanding of the effects of microwaves on the processing operations and resultant materials, so that specified and optimized microwave processing systems can be developed.

\section{Identification and evaluation of microwave athermal effect}

How could microwave energy have such advantages? Do the advantages come from inducing high temperature and pressure in sealed reactors, or by super-heating or other unknown athermal effects? Distinguishing the different advantage-producing mechanisms will lead to different strategies for efficiently utilizing the microwave method. If there are microwave athermal effects, our efforts should be focused on the development of microwave reactors that are able to enhance this effect. The optimized industrial reactors should have a method to dissipate microwave energy at an intensity level that is independent of the processing temperature but produces maximum athermal effect. If the advantages are only from the microwave-induced high temperature and pressure, the optimized reactors should have method to preserve heat so that desired hydrothermal conditions could be attained and kept with minimum consumption of microwave energy.

Preliminary evidences of the microwave athermal effects appeared from some experiments on microwave-hydrothermal synthesis of ceramic powders ${ }^{34,49-51}$, in which microwave-induced kinetic acceleration was demonstrated in comparison to conventional synthesis with nearly identical hydrothermal (temperature and pressure) conditions. These studies, however, should be refined since they did not give quantitative evaluations on the microwave effects. In these experiments, microwave heated the reaction contents to a temperature and then the power was turned down to an appropriate level so that steady-state synthesis conditions were maintained. In laboratory scale, thermal loss could be appreciable due to the small scale of the sample volume and the microwave energy for keeping the synthesis condition could be sufficient to produce observable effects. On commercial scale, however, energy accumulation from heating history becomes significant. After the system has finished the heating up stage, the accumulated thermal energy may become almost enough to maintain the processing conditions. The microwave energy, if required to compensate the thermal loss, would become insignificant. The microwaveenhanced synthesis would degenerate into conventional thermal reactions and little microwave effects could be expected.

It is worthwhile to pursue quantitative evaluation on the microwave effects. A facile approach can be evaluation of the kinetic and yield enhancements and characterization of the product structure features induced by different microwave radiation intensities at fixed temperatures (or pressures). If there are certain microwave athermal effects rather than those of microwave-induced high temperature and high pressure, they can be observed with varied microwave radiation intensities. This approach could not only distinguish the microwave athermal effects from the microwave-induced thermal effects, but can also find what intensity level can produce maximum microwave effect. Furthermore, since the dissipation of microwave energy is independent of the reaction temperature, the reaction contents could be exposed to high intensity radiation. It is therefore possible to discover new effects that have not been found in previous research.

The investigation can not be carried out with the currently available instrument. New equipment should be developed. The new type of microwave-assisted reactors should have a 
mechanism to remove the "heat waste" generated by microwave-material interactions. It could be something like a thermowell in conventional chemical reactors, but should neither expose the coolant to the microwave energy nor shield the reaction contents from the microwave radiation. For research purpose, it should have sufficient heat transfer efficiency, so that microwave energy with a wide range of intensities could be applied to the reaction contents at any reaction temperature or pressure.

\section{Study the microwave effects at different synthesis stages}

Research on ceramic sintering has suggested that sintering conditions usually affect sintering behavior not throughout the whole process, but primarily through the early stage ${ }^{52}$. The mechanism is that the initial nucleation directs the sintering process. If a larger population of nuclei has formed in the early stage, the ensuing densification will assume a higher rate and a finer microstructure will result. The microwave-assisted wet chemical synthesis, at least in the case of ceramic powder synthesis, may behave in a similar fashion to ceramic sintering, since it is also a process of nucleation and growth. The microwave effects, if they exist in both the initial and the later stages, may differently affect synthesis kinetics as well as the synthesized structures.

Comparison of the microwave effects at initial stage with that at later stages is important for the development of the synthesis systems. If the effects at the initial stage do dominate the whole process, we can focus the microwave radiation on that stage, leaving the later stages to conventional heating approaches. In the situation where the investment cost of a microwave heating facility is much higher than that of a conventional facility, such an allocation of the two kinds of energy could be an optimal strategy.

For the initial stage, it is also necessary to discern the microwave athermal effects from the effects induced by microwave-induced rapid heating. While conventional heating normally takes over an hour to heat the contents up to $200^{\circ} \mathrm{C}$, microwave heating needs only several minutes or even less. Some researchers on ceramic sintering have attributed the enhanced densification kinetics and the refined microstructures to the microwave-induced high heating $\operatorname{rate}^{53,54}$. Meanwhile, research on ceramic powder preparation also accounted for the responsibility of rapid heating for the development of monodispersed fine particles ${ }^{55}$. If the athermal effect is overwhelming, our further efforts should be devoted to the optimal microwave intensity and frequency. Otherwise, we should consider that the fast-heating function could be performed by other approaches, such as low frequency microwave or radio frequency heating, for which large capacity equipment is commercially available and the equipment cost is cheaper.

A dualfunction reactor could satisfy the study on the microwave effects at separate stages. The reactor could comprise a microwave autoclave and a conventional autoclave. The two autoclaves will be connected to each other and have a method for materials to flow in each direction. For studies on the microwave effects at initial stage, reaction contents can be first charged into the microwave autoclave and heated up by microwaves to the reaction temperature. The reaction contents would be then transferred into the conventional autoclave and the temperature would be kept constant by conventional heating. On the other hand, for studies on the microwave effects at the later stage, reaction contents can be first charged into the conventional autoclave and heated by conventional method to the reaction temperature. The reaction contents would then be transferred into the microwave autoclave and the temperature kept constant by microwave heating. Again a heat-removing device should be present in the microwave autoclave for dissipating various levels of microwave intensity without disturbing the temperature profile.

\section{Study the temperature influence on the microwave effects}

Different hydrothermal conditions may result in different microwave effects, as was revealed in the microwave-assisted synthesis of iron oxide powders. While $\alpha-\mathrm{Fe}_{2} \mathrm{O}_{3}$ seemed to be the general product under moderate microwave-hydrothermal conditions ${ }^{6}$, ?- $\mathrm{Fe}_{2} \mathrm{O}_{3}$ was obtained by 
microwave method under higher temperature and pressure ${ }^{7}$ There is a debate on the microwave acceleration effect. But a common recognition is that the high frequency electromagnetic waves have the capability of concentrating their energy onto charged ions (or molecular dipoles) instead of a conventional, unbiased distribution of the energy. For an aqueous system, although water is a good microwave absorber, its dielectric loss factor drops from above 20 to below 5 as the temperature rises from $3{ }^{\circ} \mathrm{C}$ to $95^{\circ} \mathrm{C}^{56,57}$. On the other hand, in a study of grape and sugar solutions, the loss factors of low moisture grapes and high concentration sugar solutions rise as the temperature rises ${ }^{58}$. It has found that $\mathrm{NaCl}$ and $\mathrm{CuSO}_{4}$ solutions have different dielectric responses to microwaves from that of pure water ${ }^{59}$. These findings have verified the different response of the solutes to microwave radiation in aqueous solutions and indicate that the relative microwave-responsibility of the reaction species to solvents varies with temperatures. Different temperatures may induce different distribution of microwave energy between reaction species and their solvent and result in different microwave effects. Studying the temperature influence could find the optimal hydrothermal conditions for obtaining maximum microwave effects. It is also possible to find more benefits that have not yet been revealed.

Research instruments available in most laboratories have limited temperature range for carrying out this study. The reaction vessel is typically made of Teflon, which suffers substantial deformation above $160^{\circ} \mathrm{C}$ under the autogenous pressure of aqueous solution. A strengthened shell made of polyetherimide has raised the vessel's working temperature to some extent ${ }^{60}$, however, since the maximum working temperature of polyetherimide is around $170^{\circ} \mathrm{C}^{61}$, it is unlikely to protect the vessel when processing in high temperature range comparable to conventional autoclaves. There are some microwave-reactors that are able to utilize glassware for reaction vessels ${ }^{62}$. However, when the reactor is used for microwave hydrothermal processing, the maximum processing pressure is limited to less than 25 bar, corresponding to the autogenous pressure of water vapor at $235^{\circ} \mathrm{C}$. Also, the vessel volume is only $10 \mathrm{ml}$. There is a disclosed patent for a microwave reactor using a ceramic vessel ${ }^{63}$, which could be used for high temperature synthesis, but its function should be enhanced to meet the requirements for systematic research in this regard.

Reference:

1. T. Kitamoto; "The past and future of the magnetic recording media"; Journal of the Japan Society of Powder and Powder Metallurgy, 45 [7] 615-617 (1998).

2. M. Ozaki, S. Kratohvil and E. Matijevic; "Formation of monodispersed spindle-type hematite particles"; Journal of Colloid and Interface Science, 102 [1] 146-151 (1984).

3. M. Ozaki, S. Kratohvil and E. Matijevic; "Preparation and magnetic properties of monodispersed spindle-type ?- $\mathrm{Fe}_{2} \mathrm{O}_{3}$ particles"; Journal of Colloid and Interface Science, 107 [1] 199-203 (1985).

4. M.P. Morales, T. Gonzalez-Carreno and C.J. Serna; "The formation of $\alpha-\mathrm{Fe}_{2} \mathrm{O}_{3}$ monodispersed particles in solution"; J. Mater. Res., 7 [9] 2538-2545 (1992).

5. P.D. Sawant; "Characterization of hematite sols: correlation of size, shape and percentage yield"; Bull. Mater. Sci., 20 [1] 27-35 (1997).

6. S. Komarneni, V.C. Menon and Q.H. Li; "Synthesis of ceramic powders by novel microwave-hydrothermal processing"; Ceramic Transactions, 62 1042-1122 (1996).

7. P. Rigneau, K. Bellon, I. Zahreddine and D. Stuerga; "Microwave flash-synthesis of iron oxide nanoparticles"; The European Physical Journal Applied Physics, $741-43$ (1999).

8. M.S. Whittingham; "Insertion electrodes as SMART materials: the first 25 years and future promises"; Solid State Ionics, 134 169-178 (2000).

9. M.S. Whittingham; "Electrical energy storage and intercalation chemistry"; Science, 192 [4244] 1126-7 (1976). 
10. M.S.Whittingham; "Chemistry of intercalation compounds: metal guests in chalcogenide"; Progress in Solid State Chemistry, 12 [1] 41-99 (1978).

11. M.S. Whittingham, F.R. Gamble; "Lithium intercalates of the transition metal dichalcogenides"; Mat. Res. Bull., 10 [5] 363-371 (1975).

12. T. Chirayil, P.Y. Zavalij and M.S. Whittingham; "hydrothermal synthesis of vanadium oxides"; Mat. Res. Soc. Symp. Proc., 453 135-140 (1997);

13. R. Chen and M.S. Whittingham; "Cathodic behavior of alkali manganese oxides from permanganate"; Journal of the Electrochemical Society, 144 [4] 64-67 (1997).

14. P.Y. Zavalij and M.S. Whittingham; "Structure chemistry of vanadium oxides with open frameworks"; Acta Cryst., B55 627-663 (1999).

15. S.T. Lutta, A. Dobley, K. Ngala, S. Yang, P.Y. Zavalij and M.S. Whittingham; "Vanadium oxide nanotubes: characterization and electrochemical behavior"; Mat. Res .Soc. Symp. Proc., 703 323-328 (2002).

16. D.W. Breck; Zeolite molecular sieves: structure, chemistry, and use, Wiley, New York 1974.

17. E. Chomskim, O. Dag, A. Kuperman, N. Coombs, G.A. Ozin; "New forms of luminescent silicon: silicon-silica composite mesostructures"; Chemical Vapor Deposition, 2 [1] 813 (1996).

18. G.A. Ozin; "Zeolate ligand: from hydrolysis to capped semiconductor nanoclusters"; Advanced Materials, 6 [1] 71-76 (1994).

19. O. Dag, A. Kuperman and G.A. Ozin; "Nanostructures. New forms of luminescent silicon"; Advanced Materials, 7 [1] 72-8 (1995).

20. G.A. Ozin; "Nanochemistry: synthesis in diminishing dimensions"; Advanced Materials, 4 [10], 612-49 (1992).

21. G.A. Ozin, A. Kuperman, A. Stein; "Advanced zeolite materials science"; Angew. Chem., 101 [3] 373-390 (1989).

22. G.D. Stucky, J.E. MacDougall; 'Quantum confinement and host/guest chemistry: probing a new dimension", Science, 247 [4943] 669-78 (1990).

23. R. Pool; "The smallest chemical plants"; Science, 263 [5154] 1698-1699 (1994).

24. C.-G. Wu and T. Bein; 'Conducting polyaniline filaments in a mesoporous channel host"; Science, 264 [5166] 1757-91 (1994).

25. C.-G. Wu and T. Bein; 'Conducting carbon wires in ordered, nanometer-sized channels" Science, 266 [5187] 1013-15 (1994).

26. J. Caro, F. Marlow and M. wubbenhorst; "Chromophore-zeolite composites. The organizing role of molecular sieves"; Advanced Materials, 6 [5] 413-16 (1994).

27. F. Marlow, J. Caro, L. Werner, J. Kornatowski and S. Dahne; 'Optical second harmonic generation of (dimethylamino)benzonitrile molecules incorporated in the molecular sieve AlPO4-5"; J. Phys. Chem., 97 [43] 11286-90 (1993).

28. L. Werner, J. Caro, G. Finger and J. Kornatowski; 'Optical second harmonic generation (SHG) on p-nitroaniline in large crystals of aluminophosphate AlPO4 5 and ZSM 5"; Zeolites 12 [6] 658-63 (1992).

29. M. Ehrl, F.W. Deeg, C. Brachle, O. Franke, A. Sobbi, G. Schulz-Ekloff and D. Wohrle; "High-temperature non-photochemical hole-burning of phthalocyanine-zinc derivates embedded in a hydrated AlPO4-5 molecular sieve"; J. Phys. Chem., 98 [1] 47-52 (1994).

30. D. Demuth, K.K. Unger, F. Schuth, G.D. Stucky and V.I. Srdanov; 'Photoluminescence of chromium(III)-doped silicoaluminophosphate with AFI structure"; Advanced Materials, 6 [10] 931-4 (1994).

31. R. Szostak; Molecular Sieves Principles of Synthesis and Identification, pp109-113; Van Nostrand Reinhold, New York, 1989.

32. S. L. Cresswell, J. R. Parsonage, P. G. Riby and M. J. K. Thomas; "Rapid synthesis of magnesium aluminophosphate-5 by microwave dielectric heating"; J. Chem. Soc. Dalton Trans. 2315-2316 (1995). 
33. U. Oberhagemann, M. Jeschke and H. Papp; "Synthesis of highly ordered boron-containing B-MCM-41 and pure silica MCM-41"; Microporous and Mesoporous Materials; 33 165-172 (1999).

34. M. Park and S. Komarneni; "Rapid synthesis of $\mathrm{AlPO}_{4}-11$ and cloverite by microwavehydrothermal processing"; Microporous and Mesoporous Materials, 20 39-44 (1998);

35. J.C. Carmona, R.R. Clemente and J.G. Morales; "Comparative preparation of microporous VPI-5 using conventional and microwave heating techniques"; Zeolites, 18 340-346 (1997).

36. I. Omae; Applications of Organometallic Compounds; pp1-4, John Wiley \& Sons, Inc., New York (1998).

37. A.w. Parkins and R.C. Poller; An Introduction to Organometallic Chemistry, pp11-19; Macmillan Publishers Ltd., London (1986).

38. I. Omae; Applications of Organometallic Compounds; pp45-46, 76, 82, 84, 305, 307, 338, 340; John Wiley \& Sons, Inc., New York (1998).

39. I. Omae; ibid; pp75, 85, 257, 261, 289, 338, 306, 321.

40. R. Gedye, F. Smith, and K. Westaway; "Microwaves in Organic and Organometallic Synthesis"; Journal of Microwave Power and Electromagnetic Energy, 26 [1] 3-17 (1991).

41. R. Laurent, A. Laporterie, J. Dubac and J. Berlan; "Microwave-assisted lewis acid catalysis: application to synthesis of alkyl- or arylhalogermanes"; Organometallics, 13 [6] 2493-2495 (1994).

42. S.L. VanAtta, B.A. Duclos and D.B. Green; "Microwave-assisted synthesis of Group 6 (Cr, Mo, W) zerovalent organometallic carbonyl compounds"; Organometallics, 19 2397-2399 (2000).

43. X. Fang, C.D. Simone, E. Vaccaro, S.J. Huang and D.A. Scola; "Ring-opening polymerization of $\varepsilon$-caprolactam and $\varepsilon$-caprolactone via microwave irradiation"; Journal of Polymer Science: Part A: Polymer Chemistry, 40 2264-2275 (2002).

44. L.Q. Liao, L.J. Liu, C. Zhang, F. He, R.X. Zhuo and K. Wan; "Microwave-assisted ringopening polymerization of $\varepsilon$-caprolactone"; Journal of Polymer Science: Part A: Polymer Chemistry, 40 1749-1755 (2002).

45. X. Fang, R. Hutcheon and D.A. Scola; "Microwave synthesis of poly( $\varepsilon$-caprolactam-co- $\varepsilon$ caprolactone)"; Journal of Polymer Science: Part A: Polymer Chemistry, 38 1379-1390 (2002).

46. S.E. Mallakpour, A-R. Hajipour, K. Faghihi, N. Foroughifar and J. Bagheri; "Novel optically active poly(amide-imide)s with tetrahydropyrimidinone and tetrahydro-2-thioxopyrimidine moieties by microwave-assisted polycondensition"; Journal of Applied Polymer Science, 80 2416-2421 (2001).

47. S.E. Mallakpour, A-R. Hajipour and M.R. Zamanlou; "Synthesis of optically active poly(amide-imide)s derived from N,N'-(4,4'-carbonyldiphthaloyl)-bis-L-leucine diacid chloride and aromatic diamines by microwave radiation"; Journal of Polymer Science: Part A: Polymer Chemistry, 39 177-186 (2001).

48. K.R. Carter; "Nickel(0)-mediated coupling polymerizations via microwave-assisted chemistry"; Macromolecules, 35 [18] 6757-6759 (2002).

49. S. Komarneni, R. Roy and Q.H. Li; "Microwave-hydrothermal synthesis of ceramic powders"; Mat. Res. Bull., 27 [12] 1393-1405 (1992).

50. S. Komarneni, Q. Li, K.M. Stefansson and R. Roy; "Microwave-hydrothermal processing for synthesis of electroceramic powders"; J. Mater. Res., 8 [12] 3176-3183.

51. H. Katsuki, S. Furuta and S. Komarneni; "Microwave- versus conventionalhydrothermal synthesis of hydroxyapatite crystals from Gypsum"; J. Am. Ceram. Soc., 82 [8] 2257-2259 (1999).

52. W. Komatsu, Y. Moriyoshi and Y. Ikuma; "Development of sintering theory"; Journal of the Ceramic Society of Japan, 92 [6] 299-307 (1984). 
53. Y. Ikuma, M. Nakayama, Y. Harada and T. Hiuga; "Effect of heating rate on the shrinkage of isothermal sintering"; Journal of the Ceramic Society of Japan, International Edition, 99 [6] 466-470 (1991).

54. A.G. Lanin, E.V. Marchev and S.A. Pritchin; "Non-isothermal sintering parameters and their influence on the structure and properties of zirconium carbide"; Ceramics International, 17 [5] 301-307 (1991).

55. E. Matijevic; "Monodispersed colloids: art and science"; Langmuir, 2 [1] 12-20 (1986).

56. I.S. Hudiara, "Microwave complex permitivity of water at high temperatures", IETE Technical Review, 15 [3] 221-223 (1998).

57. S. Ryynanen, P.O. Risman and T. Ohlsson, "The dielectric properties of native starch solutions - a research note", Journal of Microwave power and Electromagnetic Energy, 31 [1] 50-53 (1996).

58. T.N. Tulasidas, G.S.V. Raghavan, F. Van de Voort and R. Girard, "Dielectric properties of grapes and sugar solutions at $2.45 \mathrm{GHz}$ ", Journal of Microwave power and Electromagnetic Energy, 30 [2] 118-123 (1995).

59. G. Johri, M. Johri and J. Roberts, "Dielectric response of select ionic solutions using a load microwave cavity operating near $9 \mathrm{GHz}, 21 \mathrm{GHz}$ amd $29 \mathrm{GHz}$ as a probe", Journal of Microwave power and Electromagnetic Energy", 26 [2] 82-89 (1991).

60. W.P. Hargett, Jr.; "Sealing closure for high pressure vessels in microwave assisted chemistry"; US Patent, 6,287,526 (2001).

61. http://www.boedeker.com/ultem_p.htm

62. http://www.cem.com/

63. C.R. Strauss, R.W. Trainor, K.D. Raner and J.S. Thorn; "Batch microwave Reactor"; U.S. Patent, 5932 075, Aug.3, 1999. 